\title{
Comparison of Variable and Constant Loading for Mesophilic Food Waste Digestion in a Long-Term Experiment
}

\author{
He Song ${ }^{1,2, *}$, Yue Zhang ${ }^{2}\left(\mathbb{D}\right.$, Sigrid Kusch-Brandt ${ }^{2,3, * \mathbb{C}}$ and Charles J. Banks ${ }^{2}$ \\ 1 Biomass Group, College of Engineering, Nanjing Agricultural University, 40 Dianjiangtai Road, \\ Nanjing 210031, China \\ 2 Water and Environmental Engineering Group, University of Southampton, Southampton SO16 7QF, UK; \\ Y.Zhang@soton.ac.uk (Y.Z.); C.J.Banks@soton.ac.uk (C.J.B.) \\ 3 Civil, Environmental and Architectural Engineering, University of Padua, 35131 Padua, Italy \\ * Correspondence: H.Song@soton.ac.uk (H.S.); mail@sigrid-kusch.eu (S.K.-B.)
}

Received: 30 January 2020; Accepted: 3 March 2020; Published: 10 March 2020

\begin{abstract}
Operators of commercial anaerobic digestion (AD) plants frequently note the challenge of transferring research results to an industrial setting, especially in matching well-controlled laboratory studies at a constant organic loading rate (OLR) with full-scale digesters subject to day-to-day variation in loadings. This study compared the performance of food waste digesters at fluctuating and constant OLR. In a long-term experiment over nearly three years, variable daily OLR with a range as wide as 0 to $10.0 \mathrm{~g} \mathrm{VS} \mathrm{L}^{-1}$ day $^{-1}$ (weekly average $5.0 \mathrm{~g} \mathrm{VS} \mathrm{L}^{-1}$ day $^{-1}$ ) were applied to one laboratory-scale digester, while a pair of control digesters was operated at a constant daily loading of $5.0 \mathrm{~g} \mathrm{VS} \mathrm{L}^{-1}$ day $^{-1}$. Different schemes of trace elements (TE) supplementation were also tested to examine how they contributed to process stability. Variable loading had no adverse impact on biogas production or operational stability when $11 \mathrm{TE}$ species were dosed. When TE addition was limited to cobalt and selenium, the stability of the variable-load digester was well maintained for nearly 300 days before the experiment was terminated, while the control digesters required re-supplementation with other TE species to reverse an accumulation of volatile fatty acids. This work demonstrated that variation in daily OLR across quite a wide range of applied loadings is possible with no adverse effects on methane production or stability of food waste digestion, giving confidence in the transferability of research findings. The positive effect of variable OLR on TE requirement requires further investigation considering its practical significance for AD industry.
\end{abstract}

Keywords: variable loading; food waste; anaerobic digestion; trace elements; cobalt; selenium; process stability

\section{Introduction}

Food waste is a ubiquitous and energy-rich organic material with a high potential to be used in anaerobic digestion (AD) for biogas production [1-3], but it can pose challenges with regard to maintaining process stability and favourable long-term performance of the digester [4,5]. In single-stage continuous stirred tank reactor (CSTR) digestion, which is the most common type of AD plant operated in practice, mono-digestion of food waste without the addition of stabilising agents is limited to an organic loading rate (OLR) of up to $2.0 \mathrm{~g} \mathrm{VS} \mathrm{L}^{-1} \mathrm{~d}^{-1}$ (grams volatile solids per litre digester working volume and day) [6-8], while even lower OLRs may be necessary to maintain a stable process [9]. OLR is an important operational parameter and an indicator of the commercial capacity of the digester; an elevated OLR is usually desirable as this means higher throughput of organic material and therefore a higher volumetric methane production potential. Overloading or shock loading may lead to instability 
and process failure, however, for two interlinked reasons: (1) disturbance or breakdown of the delicate balance between production of volatile fatty acids (VFAs) through hydrolysis, acidogenesis and acetogenesis on one hand and consumption of VFAs through methanogenesis on the other hand [10]; and (2) washing out of slow-growing anaerobic microbial biomass when hydraulic retention time is reduced as a result of overloading [11]. A disturbance in the metabolic balance is typically accompanied by declining biogas and methane yields, VFA accumulation and $\mathrm{pH}$ decrease [10,12], while overloading without imbalance may be indicated by a simple drop in specific biogas and methane yields as the time available for feedstock degradation is reduced $[10,13]$. AD of readily degradable organic material such as food waste usually suffers from the first problem, and irreversible acidification may occur as a result of digester overload [5,14]. In food waste AD, deficiency of trace elements (TEs) was identified as a major factor adversely affecting process stability [15-17].

A common strategy to increase OLR and avoid process failure or inhibition is co-digestion of food waste with other substrates $[8,18-20]$. As an alternative, TE supplementation was found to be an effective strategy to ensure stable operation when using only food waste (mono-digestion) even under an elevated OLR [21-23]. Banks et al. [15] found that with supplementation of TEs (Co, Se) the OLR in mono-digestion of food waste could be increased to $5 \mathrm{~g} \mathrm{VS} \mathrm{L}^{-1} \mathrm{~d}^{-1}$. After supplementation of deficient TEs (Co, Fe, Mo, Ni and Se), Voelklein et al. [6] observed the recovery of a strongly inhibited food waste mono-digestion process (VFA accumulation was overcome), followed by stable digestion at substantially higher loading rates of up to $5 \mathrm{~g} \mathrm{VS} \mathrm{L}^{-1} \mathrm{~d}^{-1}$. Jo et al. [7] successfully increased the OLR of TE-supplemented food waste digestion to $5 \mathrm{~g} \mathrm{VS} \mathrm{L}^{-1} \mathrm{~d}^{-1}$ in a single-stage AD system, while a two-stage system failed at this OLR with same TE supplementation. Based on these results, an OLR of $5 \mathrm{~g} \mathrm{VS} \mathrm{L}^{-1} \mathrm{~d}^{-1}$ is feasible for food waste mono-digestion in a single-stage CSTR system supplemented with appropriate levels of TEs.

Zhang et al. [9] observed declining concentrations of Cobalt (Co), Molybdenum (Mo), Nickel (Ni) and Iron (Fe) during long-term food waste mono-digestion, but supplementation of these TEs did not achieve stable operation at elevated OLRs. At such elevated OLRs (5 g VS L $\left.{ }^{-1} \mathrm{~d}^{-1}\right)$, Cobalt (Co) was reported as likely to become limiting due to its role either in acetate oxidation or in hydrogenotrophic methanogenesis; otherwise, Selenium (Se) was identified as the limiting TE [15].

Controlling for a constant OLR is common practice in scientific studies at laboratory scale, but is not a simple task in a full-scale AD plant. It requires constant monitoring of the feedstock composition and advanced management of organic material flows during intermediate storage of degradable substrates. In practice, commercial digesters are therefore run with variable organic loading rates, and this difference is often cited by the industry as a reason why it may be challenging to transfer research results or to match the performance achieved in well-controlled laboratory studies. Research endeavours to date have provided some valuable evidence on the links between AD system performance and transient or shock changes in organic loading. In a single-stage food waste digestion process, Grimberg et al. [24] observed a lower methane yield under variable loading, but the methane yield was higher in two-stage digestion; while this shows the possibility of reduced process performance, it does not clarify the influential factors. Kim and Lee [25] found that $\mathrm{pH}$ control had a crucial effect on the resilience and robustness of the microbial community under shock loading, whereas the archaeal community was less affected. Ferguson et al. [26] demonstrated that multiple changes in OLR, based on using different co-substrates, could increase the resilience of the process, and suggested to use varying OLRs to manipulate the microbial community; however, decreases in biogas and methane production were observed, and their study operated at very short hydraulic retention times (HRT) and did not consider food waste. Essentially, the findings from these experiments provide some information on the response of anaerobic digesters to loading perturbation and insights to the recovery patterns. To guide real-world digester operation, however, a better understanding is still needed of potential differences between results from carefully controlled trials at constant OLR and those at variable loading, and also of factors affecting the performance of variable loading digesters. 
This work aimed to test the performance of food waste digestion under different variable loading patterns at a relatively high average OLR of $5 \mathrm{~g} \mathrm{VS} \mathrm{L}^{-1} \mathrm{~d}^{-1}$, and to compare this with digesters at a constant OLR. Stability of the process was assessed by monitoring several indicators, including VFA concentrations and methane production. The response of the digestion process to trace elements limitation was also considered.

\section{Materials and Methods}

\subsection{Materials}

The batches of food waste used came from the waste transfer station operated by Veolia Environmental Services in Otterbourne, Hampshire, UK. Fresh food waste was transferred to the laboratory of University of Southampton in sealed plastic barrels; a total of nine batches of substrate were used in the study (Table 1). After manual removal of non-biodegradable materials, the feedstock was homogenised using a macerating grinder (S52/100 Waste Disposer, IMC Limited, Wrexham, UK). The macerated substrate was stored at $-20^{\circ} \mathrm{C}$ and thawed before use. Table 1 summarises the substrate characteristics (macerated food waste) of each feedstock batch used during the long-term experiment over nearly 3 years.

Table 1. Characteristics of food waste used in this study (after manual removal of non-biodegradable components and maceration): total solids (TS), volatile solids (VS), total Kjeldahl nitrogen (TKN), trace elements.

\begin{tabular}{|c|c|c|c|c|c|c|c|c|c|c|}
\hline & \multirow{2}{*}{$\begin{array}{l}\text { Days } \\
\text { in Use }\end{array}$} & \multirow{2}{*}{$\begin{array}{c}\mathrm{TS}^{1} \\
\left(\mathrm{~g} \mathrm{~kg}^{-1}\right)\end{array}$} & \multirow{2}{*}{$\begin{array}{c}\mathrm{VS}^{1} \\
\left(\mathrm{~g} \mathrm{~kg}^{-1}\right)\end{array}$} & \multirow{2}{*}{$\begin{array}{c}\text { VS/TS } \\
(\%)\end{array}$} & \multirow{2}{*}{$\begin{array}{c}\text { TKN }^{1} \\
\left(\mathrm{~g} \mathrm{~kg}^{-1}\right)\end{array}$} & \multicolumn{5}{|c|}{ Trace Elements ${ }^{1}\left(\mathrm{mg} \mathrm{kg}^{-1}\right)$} \\
\hline & & & & & & Co & Se & $\mathrm{Ni}$ & Mo & $\mathrm{Fe}$ \\
\hline Batch 1 & $0-159$ & 211.8 & 187.9 & 88.8 & 6.30 & 0.013 & 0.050 & 0.125 & 0.129 & 36.3 \\
\hline Batch 2 & $160-292$ & 238.2 & 224.8 & 94.4 & 7.57 & 0.052 & 0.059 & 0.330 & 0.197 & -2 \\
\hline Batch 3 & $293-348$ & 233.3 & 218.7 & 93.7 & 7.82 & 0.007 & 0.063 & 0.105 & 0.078 & 16.6 \\
\hline Batch 4 & $349-496$ & 241.7 & 226.7 & 93.8 & 6.35 & 0.018 & 0.019 & 0.168 & 0.120 & -2 \\
\hline Batch 5 & $497-579$ & 230.4 & 208.0 & 90.3 & 6.18 & -2 & -2 & -2 & -2 & -2 \\
\hline Batch 6 & $580-699$ & 241.6 & 230.8 & 95.5 & 7.20 & 0.013 & 0.018 & 0.550 & 0.106 & -2 \\
\hline Batch 7 & $700-775$ & 239.1 & 222.2 & 92.9 & 7.58 & 0.022 & 0.036 & 0.100 & 0.190 & -2 \\
\hline Batch 8 & $776-877$ & 237.2 & 211.9 & 89.3 & -2 & 0.024 & 0.042 & 0.167 & 0.221 & -2 \\
\hline Batch 9 & 878-1068 & 249.7 & 232.2 & 93.0 & -2 & -2 & -2 & -2 & -2 & -2 \\
\hline Mean ${ }^{3}$ & & 236.3 & 218.5 & 92.4 & 6.89 & 0.022 & 0.039 & 0.233 & 0.149 & 31.2 \\
\hline
\end{tabular}

${ }^{1}$ Solids data are averages of duplicate analyses; all results are expressed on a fresh matter basis. ${ }^{2}$ Not measured. ${ }^{3}$ Weighted average, considering the number of days the feedstock of each batch was used for the daily loading of the digesters.

The inoculum used came from digesters in the same laboratory that had previously been operated for more than 500 days on food waste obtained from the same source [27]. The inoculum had a $\mathrm{pH}$ of 7.69 , a total ammonium nitrogen (TAN) content of $2.93 \mathrm{~g} \mathrm{~L}^{-1}$, an intermediate/partial alkalinity (IA/PA) ratio of 0.34 and a total volatile fatty acids (VFA) content of $<500 \mathrm{mg} \mathrm{L}^{-1}$. Digesters labelled as F5\&6 in the previous work of Jiang [27] were used as constant loading controls (CL1 and CL2) in this study, while the previously labelled digester F11 was used for variable loading (VL) in this work. Before use in this study, all three digesters had been operated at OLR $5.5 \mathrm{~g} \mathrm{VS} \mathrm{L}^{-1} \mathrm{~d}^{-1}$ for more than 150 days with F5\&6 supplemented with $\mathrm{Co}$, Se and Mo and F11 with 11 TEs, and these were the initial conditions for this study.

Eleven trace elements were used in this research, supplied in accordance with the strategies described in the results section. For this purpose, each individual trace element stock solution was made using the compounds listed in Table 2 and kept in the refrigerator when not in use. The dosing strength of each trace element was chosen based on the results of previous studies on trace elements supplementation during the anaerobic digestion of food waste [15]. 
Table 2. Trace elements used in this study.

\begin{tabular}{ccc}
\hline Element & Compound Used & $\begin{array}{c}\text { Supplementation Strength in the Digester } \\
\text { (mg L } \mathbf{L}^{-1} \text { Digester Working Volume) }\end{array}$ \\
\hline Cobalt $(\mathrm{Co})$ & $\mathrm{CoCl}_{2} \cdot 6 \mathrm{H}_{2} \mathrm{O}$ & 1.0 until day 776, 0.3 from day 777 on $^{1}$ \\
Selenium $(\mathrm{Se})$ & $\mathrm{Na}_{2} \mathrm{SeO}_{3}$ & 0.2 \\
Molybdenum $(\mathrm{Mo})$ & $\left(\mathrm{NH}_{4}\right)_{6} \mathrm{Mo}_{7} \mathrm{O}_{24} \cdot 4 \mathrm{H}_{2} \mathrm{O}$ & 0.2 \\
Tungsten $(\mathrm{W})$ & $\mathrm{Na}_{2} \mathrm{WO}_{4} \cdot 2 \mathrm{H}_{2} \mathrm{O}$ & 0.2 \\
Nickel $(\mathrm{Ni})$ & $\mathrm{NiCl}_{2} \cdot 6 \mathrm{H}_{2} \mathrm{O}$ & 1.0 \\
Iron $(\mathrm{Fe})$ & $\mathrm{FeCl}_{2} \cdot 4 \mathrm{H}_{2} \mathrm{O}$ & 5.0 \\
Aluminium (Al) & $\mathrm{AlCl}_{3} \cdot 6 \mathrm{H}_{2} \mathrm{O}$ & 0.1 \\
Boron (B) & $\mathrm{H}_{3} \mathrm{BO}_{3}$ & 0.1 \\
Copper (Cu) & $\mathrm{CuCl}_{2} \cdot 2 \mathrm{H}_{2} \mathrm{O}$ & 0.1 \\
Manganese $(\mathrm{Mn})$ & $\mathrm{MnCl}_{2} \cdot 6 \mathrm{H}_{2} \mathrm{O}$ & 1.0 \\
Zinc $(\mathrm{Zn})$ & $\mathrm{ZnCl}_{2}$ & 0.2 \\
\hline
\end{tabular}

${ }^{1}$ The supplementation strength was reduced to study the resilience of the process under trace element limitation (see Section 2.3 for details).

\subsection{Description of Digesters}

Laboratory-scale CSTR digesters were used, each with a total volume of $5 \mathrm{~L}$ and a working volume of $4 \mathrm{~L}$. The digesters were constructed of PVC tube with gas-tight top and bottom plates. The top plate was fitted with a gas outlet, a feed port sealed with a rubber bung, and a draught tube liquid seal through which an asymmetric bar stirrer was inserted with a 40-rpm motor mounted directly on the top plate. Temperature was controlled at $37.0 \pm 0.5{ }^{\circ} \mathrm{C}$ by circulating water from a thermostatically controlled bath through a heating coil around the digesters.

Digesters were fed daily throughout the whole experiment and digestate was removed twice a week to maintain an approximately constant working volume. Semi-continuous operation was achieved by removing digestate through the outlet port in the base plate before adding feed via the inlet in the top plate.

\subsection{Experimental Procedure}

The experimental work was carried out as a long-term study over a period of 1068 days. Three digesters were used. Digesters CL1 and CL2 were used as control and operated at constant loading, while digester VL was exposed to variable OLR. The operational scheme of the whole work is plotted in Figure 1. To establish a baseline, the digesters were first run in parallel for a period of 105 days to confirm stable and repetitive operation at a constant loading of $5.5 \mathrm{~g} \mathrm{VS} \mathrm{L}^{-1} \mathrm{~d}^{-1}$ (organic loading per digester working volume and day).

From day 105 on, the digesters were no longer subjected to the same OLR. The OLR of digester VL was increased gradually over a period of 2 weeks to $6.0 \mathrm{~g} \mathrm{VS} \mathrm{L}^{-1} \mathrm{~d}^{-1}$, to provide some slight additional acclimatisation to intermittent increases in loading. This steady OLR was maintained for a period of 8 weeks (days 123-181); then, from day 182 on, digester VL was operated with variable loading, to investigate how digester performance was affected by load fluctuation. During the period of variable loading the digester received a weekly average OLR of $5 \mathrm{~g} \mathrm{VS} \mathrm{L}^{-1} \mathrm{~d}^{-1}$. From day 182 to day 629 (64 weeks), the loading in S2 fluctuated from 2.5 to $7.5 \mathrm{~g} \mathrm{VS} \mathrm{L}^{-1} \mathrm{~d}^{-1}$. For the first 6 weeks of this period, the daily loading was selected from values at increments of $0.5 \mathrm{~g} \mathrm{VS} \mathrm{L}^{-1} \mathrm{~d}^{-1}$. From day 225 to day 629 the daily loading was obtained from a purpose-designed random number selection routine working at increments of $0.1 \mathrm{~g} \mathrm{VS} \mathrm{L}^{-1} \mathrm{~d}^{-1}$. From day 630 to 965 (48 weeks), the range of loading variation was increased to between 0 and $10 \mathrm{~g} \mathrm{VS} \mathrm{L}^{-1} \mathrm{~d}^{-1}$. For the first 25 weeks of this period, the daily loading was obtained from the selection routine as before, while for the next 23 weeks, a pattern of a period of variable loadings between $0-10 \mathrm{~g} \mathrm{VS} \mathrm{L}^{-1} \mathrm{~d}^{-1}$ followed by one or two weeks of constant loading at $5 \mathrm{~g} \mathrm{VS} \mathrm{L}^{-1} \mathrm{~d}^{-1}$ was tested to increase the complexity of the load fluctuation. In contrast to digester VL, after the initial phase of operation in parallel the OLR on control digesters CL1\&2 was 
reduced to $5.0 \mathrm{~g} \mathrm{VS} \mathrm{L}^{-1} \mathrm{~d}^{-1}$ on day 119 and kept at this level until day 1068. During the last 14 weeks (days 966-1068), the OLR of digester VL was also set to this level and all digesters were again operated at equal OLR.

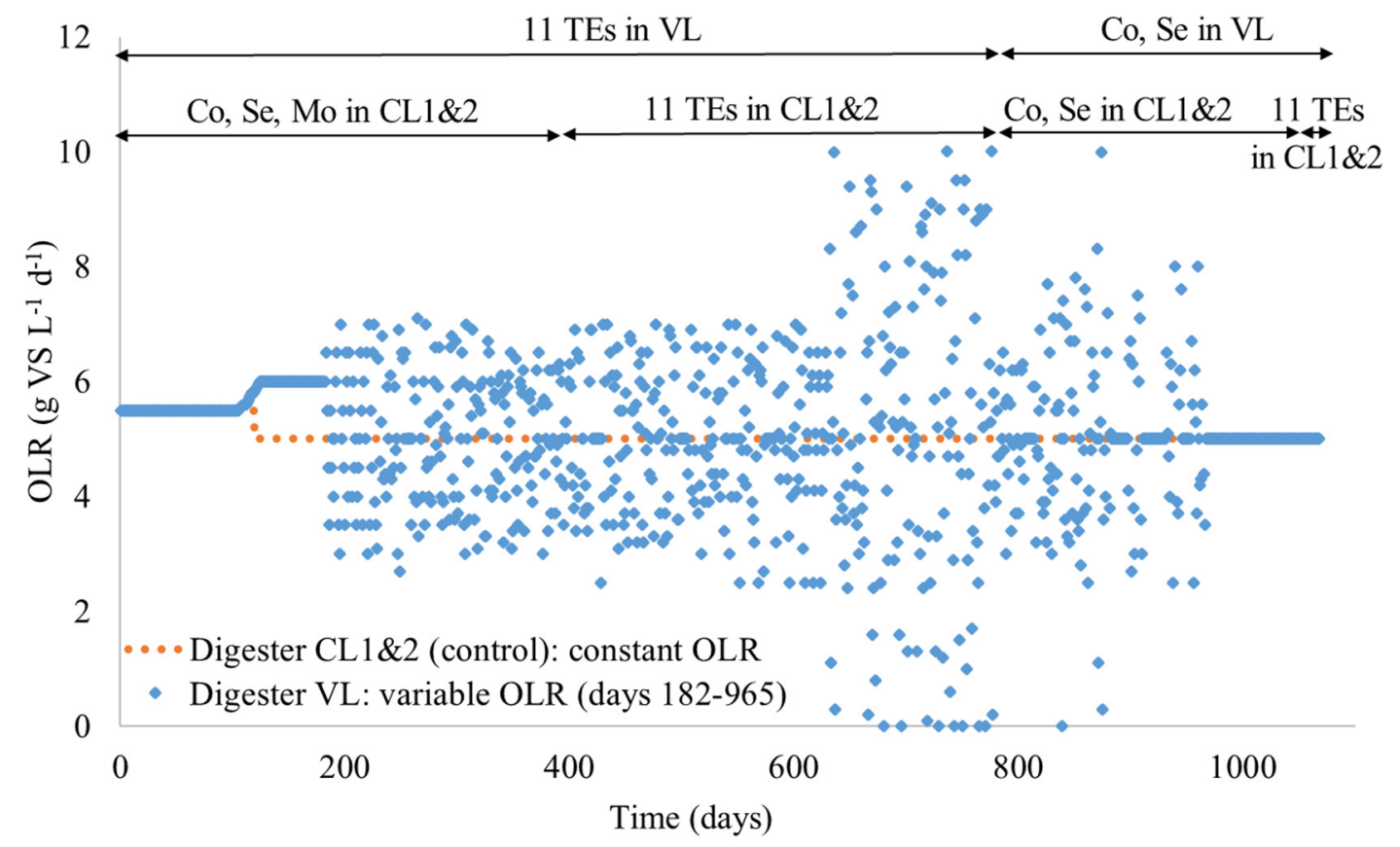

Figure 1. Operational scheme of digesters used in this study, including organic loading rate (OLR) change and trace elements (TE) supplementations (VL: digester with variable loading, CL: digester with constant loading).

The control digesters CL1\&2 were supplemented with Co, Se and Mo as the most essential trace elements [15] during the first 56 weeks, then with all 11 trace elements for a period of 55 weeks (days 392-776). In contrast, digester VL was supplemented with all 11 trace elements during these 111 weeks to ensure that TEs were not limiting when the OLR variation scheme was applied. From day 777 on, the TE supplementation was replaced in all digesters with a dosage of $0.3 \mathrm{mg} \mathrm{L}^{-1} \mathrm{Co}$ and $0.2 \mathrm{mg}^{-1}$ $\mathrm{L}^{-1}$ Se in order to investigate the resistance of each digester to TE limitation. Control digesters CL1\&2 were supplemented with the 11 TEs from day 1056 on, to test whether the observed process inhibition could be reduced by this measure; this is described with the results and their discussion (Section 3).

\subsection{Laboratory Analyses}

Total solids (TS) and volatile solids (VS) were measured according to Standard Method 2540G [28]. $\mathrm{pH}$ was measured using a Jenway $3310 \mathrm{pH}$ meter (Bibby Scientific Ltd., Stone, UK) with electrode and thermometer, calibrated in buffers at $\mathrm{pH}$ 4.0, 7.0 and 9.2 (Fisher Scientific, Loughborough, UK). Alkalinity was measured by titration with $0.25 \mathrm{~N} \mathrm{H}_{2} \mathrm{SO}_{4}$ to endpoints of $\mathrm{pH} 5.75$ and 4.3, allowing calculation of total alkalinity (TA), partial alkalinity (PA) and intermediate alkalinity (IA) [29]. Total Kjeldahl nitrogen (TKN) and total ammonium nitrogen (TAN) were determined using a Kjeltech block digester and ammonia by steam distillation unit according to the manufacturer's instructions (Büchi, Oldham, UK). Volatile fatty acids (VFA) were measured by Shimazdu GC-2010 gas chromatograph (Shimadzu, Milton Keynes, UK) equipped with a capillary column type SGE BP21 and a flame ionisation detector. The temperature at the injector and detector were maintained at $200{ }^{\circ} \mathrm{C}$ and $250{ }^{\circ} \mathrm{C}$. Helium was used as the carrier gas at a flow rate of $190.8 \mathrm{~mL} \mathrm{~min}^{-1}$. 


\subsection{Quantity and Composition of Biogas, Calculation of the Rolling Average Volumetric Methane Production (VMP)}

Gas production was measured using tipping-bucket gas counters, with collection in gas-impermeable bags. Calibration was carried out by measuring the volume of biogas using the weight-based water displacement method [30], and values are corrected to standard temperature and pressure (273.15 K, $1 \mathrm{~atm}(1.01325 \mathrm{bar}), \mathrm{STP})$. Carbon dioxide and methane concentrations were monitored using a Varian star 3400 CX Gas Chromatograph (Varian, Oxford, UK) with argon as the carrier gas.

The variation of the daily loading makes it difficult to directly compare the daily methane production between variable and constant loading digesters. Therefore, the 28-days rolling average volumetric methane production (VMP) was calculated, using the volumetric methane production of the 28 days before the specific date. The rolling average approach creates a series of averages over the studied time period. The rolling average VMP is reported in litres methane per litre active digester volume and day $\left(\mathrm{L} \mathrm{CH}_{4} \mathrm{~L}^{-1} \mathrm{~d}^{-1}\right)$.

Data supporting this study are available as Supplementary Materials from the University of Southampton repository (https://doi.org/10.5258/SOTON/D1266).

\section{Results and Discussion}

\subsection{Process Stability under Variable and Constant Loading of Digester}

The profiles of volatile fatty acids, $\mathrm{pH}$, alkalinity and ammonia provide information on the stability of the digestion process. From day 105 on, the digesters were no longer operated at the same OLR. In Figure 2 it can be seen that elevated VFA concentrations in CL1\&2 were more frequent and more pronounced than in digester VL. This pattern, however, did not occur during periods where all 11 trace elements were supplemented; under operation with full TE addition, all digesters showed low total VFA concentrations and no acids were accumulated. Acetic acid accounted for most of the VFA when increased concentrations were observed, and it degraded very quickly. VFAs with inhibitory impact, in particular propionic, iso-butyric and iso-valeric acid $[9,15]$, were found only in low concentrations less than $500 \mathrm{mg} \mathrm{L}^{-1}$. This indicates that there was no risk of process instability and confirms that with appropriate supplementation of trace elements, mono-digestion of food waste is a stable process in long-term operation (here more than 110 weeks).

Most notably, from day 777 on, when supplementation with the 11 TEs was stopped and only Selenium and a reduced dosage of Cobalt were added, digester VL showed less VFA accumulation compared to digesters CL1\&2. A delay in reaction to this change in operation is visible for all digesters, reflecting the time required for washing-out of the earlier dosages of the 11 TEs. After day 970, some elevated acid concentrations were detected in digester VL, but this was a short-term phenomenon only and observed concentrations were moderate (less than $1600 \mathrm{mg} \mathrm{L}^{-1}$ ). In contrast, VFAs started to accumulate in both CL1\&2 seven weeks after dosage with the 11 TEs had been stopped. From day 950 on, the concentration of total VFAs fluctuated at around $3000-4000 \mathrm{mg} \mathrm{L}^{-1}$ in CL1 and 8000-10000 $\mathrm{mg} \mathrm{L}^{-1}$ in CL2. Acetic acid remained the dominant component in CL1. However, propionic, iso-butyric and iso-valeric acid, reported to be most influential to inhibit mono-digestion of food waste under trace element limitation [9,23], also occurred in high concentrations with propionic acid, even becoming the dominant species in CL2. It can be assumed that this accumulation of acids was induced by trace element limitations. This assumption is confirmed by the observation that, when supplementation with 11 TEs to digesters CL1\&2 began again from day 1056 on, total VFA decreased very rapidly to below $500 \mathrm{mg} \mathrm{L}^{-1}$ (Figure 2).

Small differences in VFA accumulation were also observed early in the experimental period, with VFA peaks seen in both steady OLR digesters at around days 290 and 330, which did not appear in the variable load digester. The reason for this is unknown, but may be related to the different TE supplementation at the time and in the period of operation preceding the start of this trial, 
when digester VL was supplemented with $11 \mathrm{TE}$, while CL1\&2 received only Co, Se and Mo. These peaks were transient, however, and were followed by a period of 520 days equivalent to around 12 HRT of stable operation in all digesters. It is therefore considered unlikely that the earlier difference in TE supplementation had a major effect on pattern of VFA accumulation in the final days (day 850-1068) of the trial.

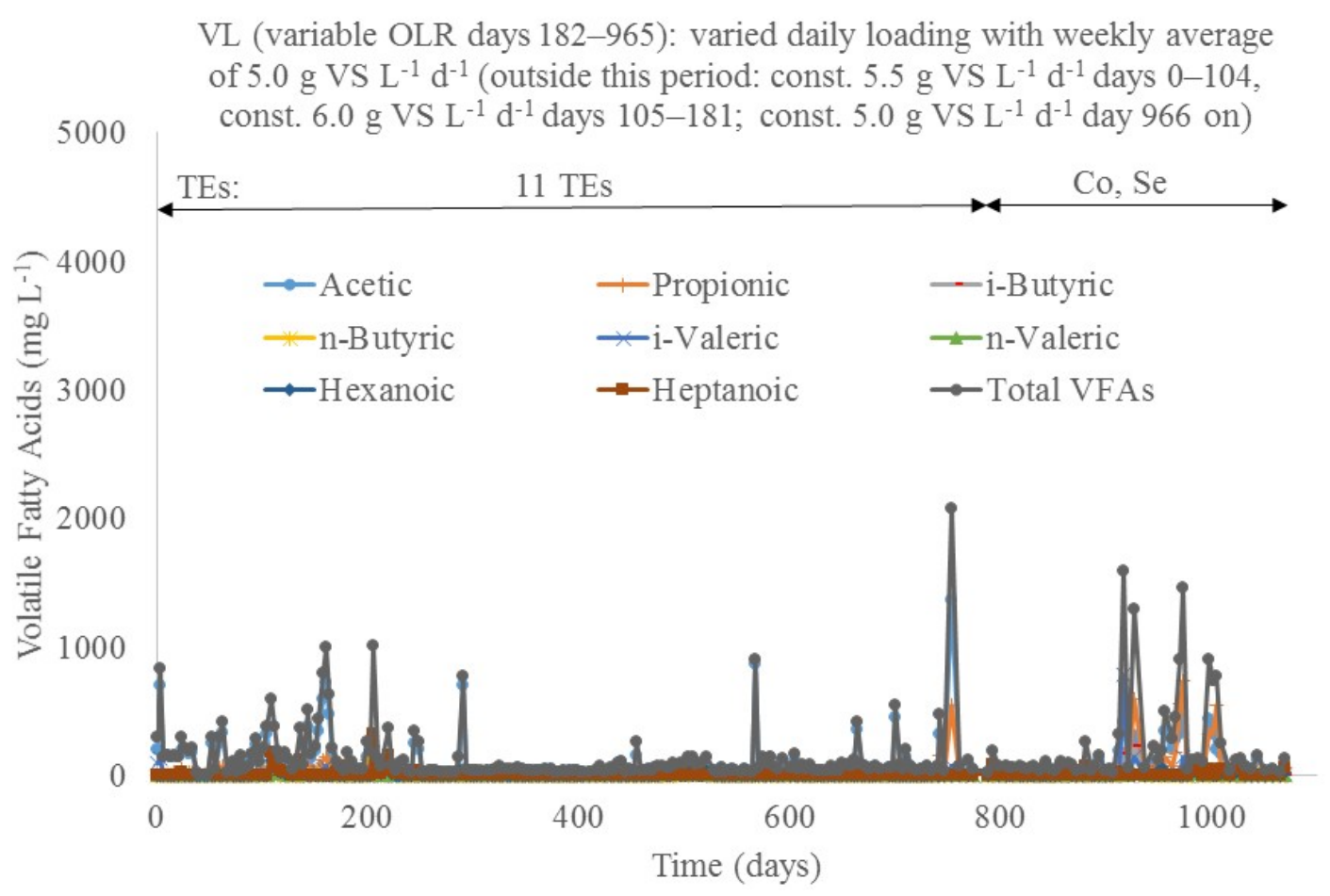

(a)

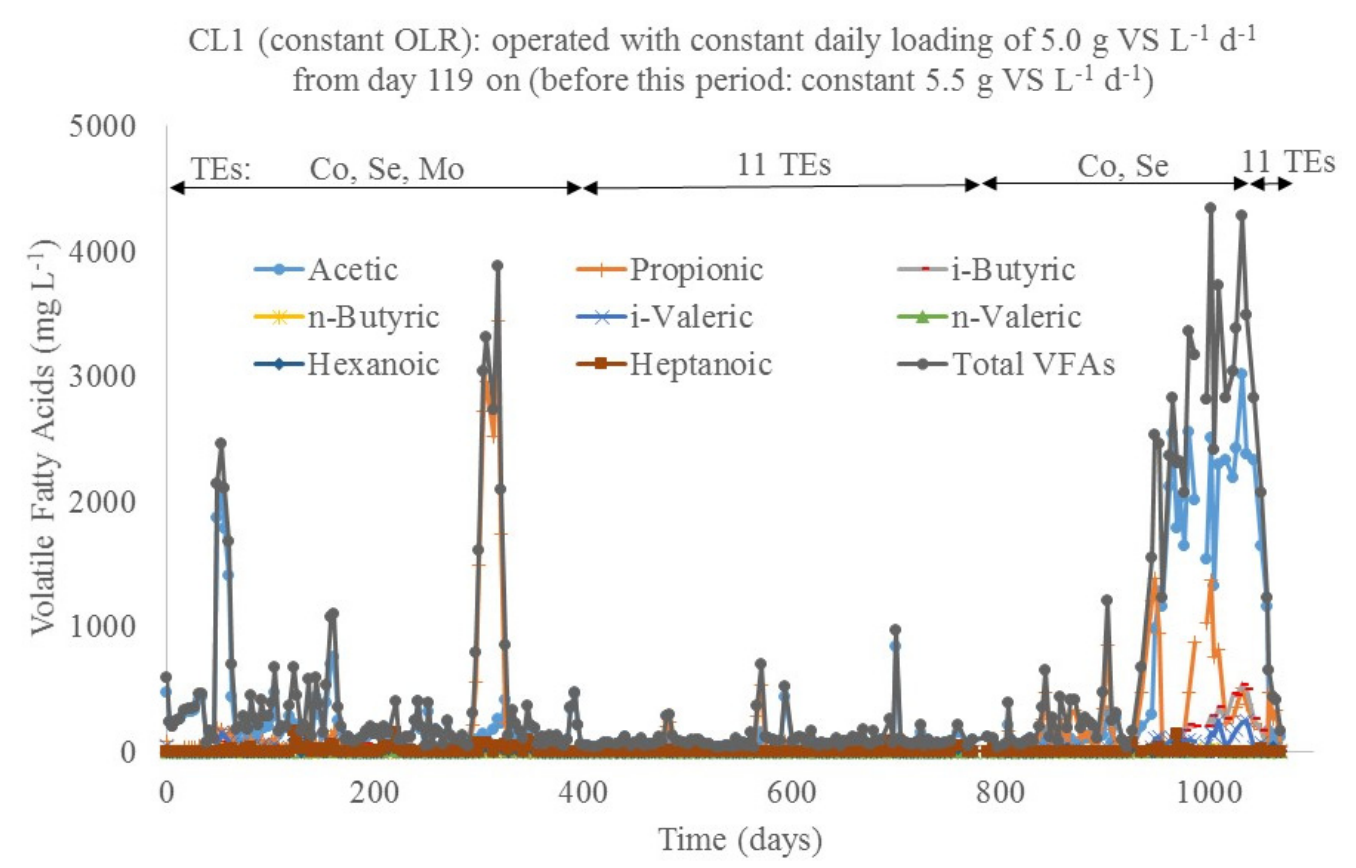

(b)

Figure 2. Cont. 


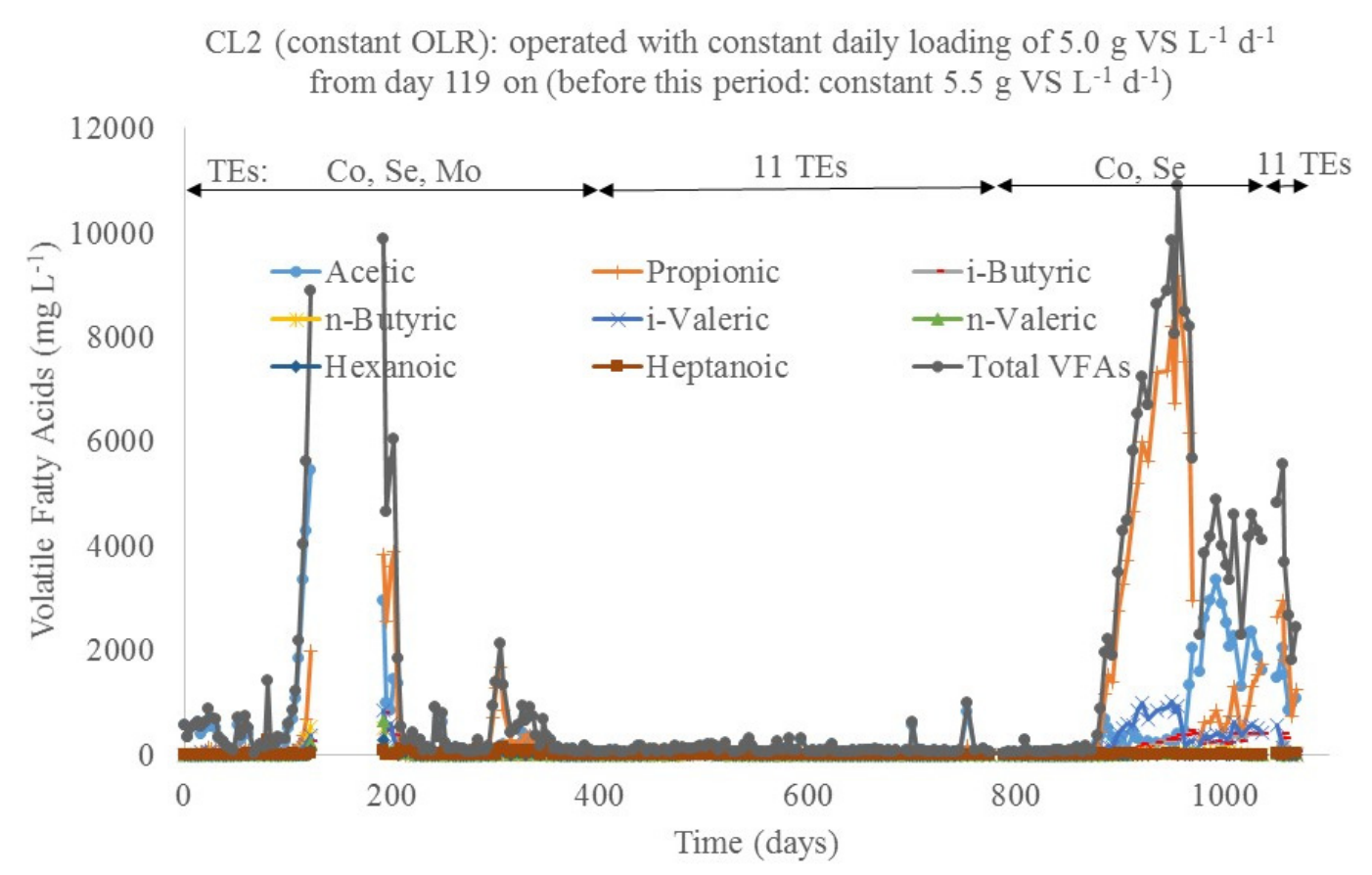

(c)

Figure 2. Volatile fatty acids (VFA) profiles: (a) Digester VL with varying organic loading rate; (b) Control digester CL1; (c) Control digester CL2. (Note: 1. These digesters had the same constant OLR until day 105 and from day 966 on, but not always the same TE supplementation scheme; 2. The digester CL2 suffered from a severe operation problem on day 103: water in biogas counter was siphoned back to the digester causing disturbance and VFA increase for a period of 200 days. The VFA peak after that event was not displayed fully in Figure 2c due to its scale; 3 . The y-axis scale of control digester CL2 is different from others due to its high VFA peak around day 1000.).

The $\mathrm{pH}$ remained stable at around $7.80 \pm 0.20$ over the whole experimental period in all digesters, which is a favourable level for anaerobic digestion. Changes in $\mathrm{pH}$ were linked to varying TKN concentrations in the feedstock affecting the digester TAN content (Figure 3b), rather than to VFA accumulation. TAN concentrations in both digesters fluctuated between 2.0 and $5.0 \mathrm{~g} \mathrm{~L}^{-1}$, with the fluctuations reflecting differences in the properties of food waste batches as shown in Table 1 . As reviewed by Yenigün and Demirel [31], a wide range of ammonia concentrations have been reported to cause inhibition in mesophilic anaerobic digestion, from 2.8 to $6.0 \mathrm{~g} \mathrm{~L}^{-1}$; however, previous work with food waste of the same type has shown stable mesophilic operation at TAN concentrations similar to those found here [15], and thus, ammonia concentrations in this study are unlikely to have significantly affected process stability or methane production.

While total VFA concentrations in this study did not correlate with $\mathrm{pH}$ values or TAN concentrations, elevated concentrations of VFA corresponded to higher IA/PA ratios (Figure 3c). For CL1\&2, this can be seen during the first months of the experiment, during the short period of slight VFA increase (mainly propionic acid) around day 307 and during the last months of the experiment. The IA:PA ratio remained at $0.30 \pm 0.10$ during the whole operation. As with the $\mathrm{pH}$ value, this parameter was located in an optimal range, indicating a favourable buffering capacity and good operational stability. 


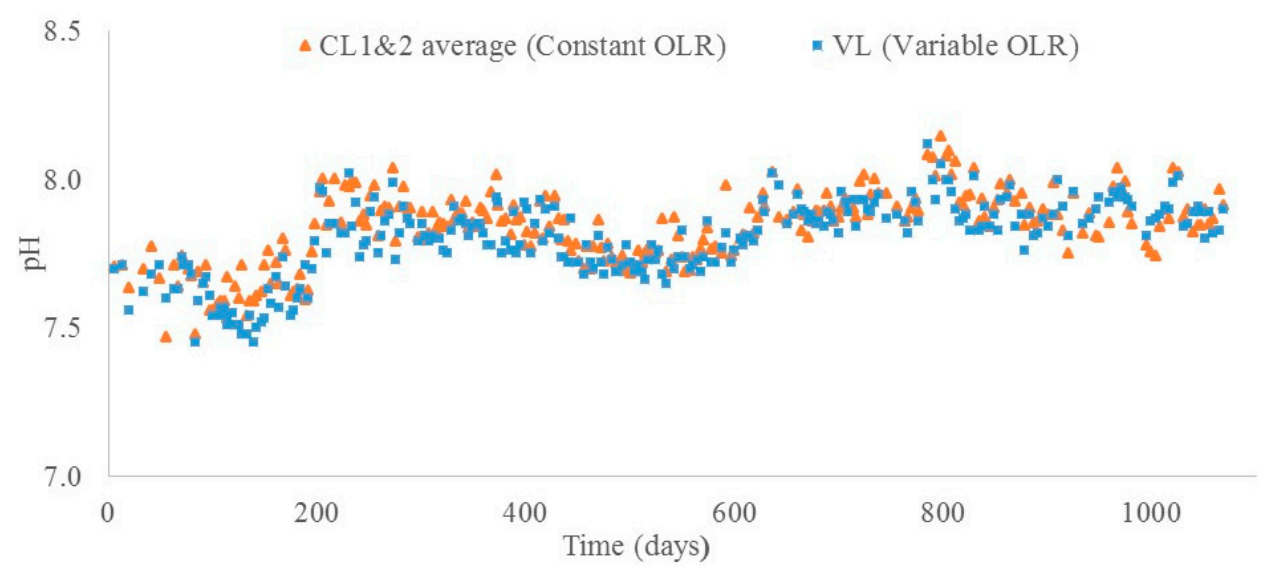

(a)

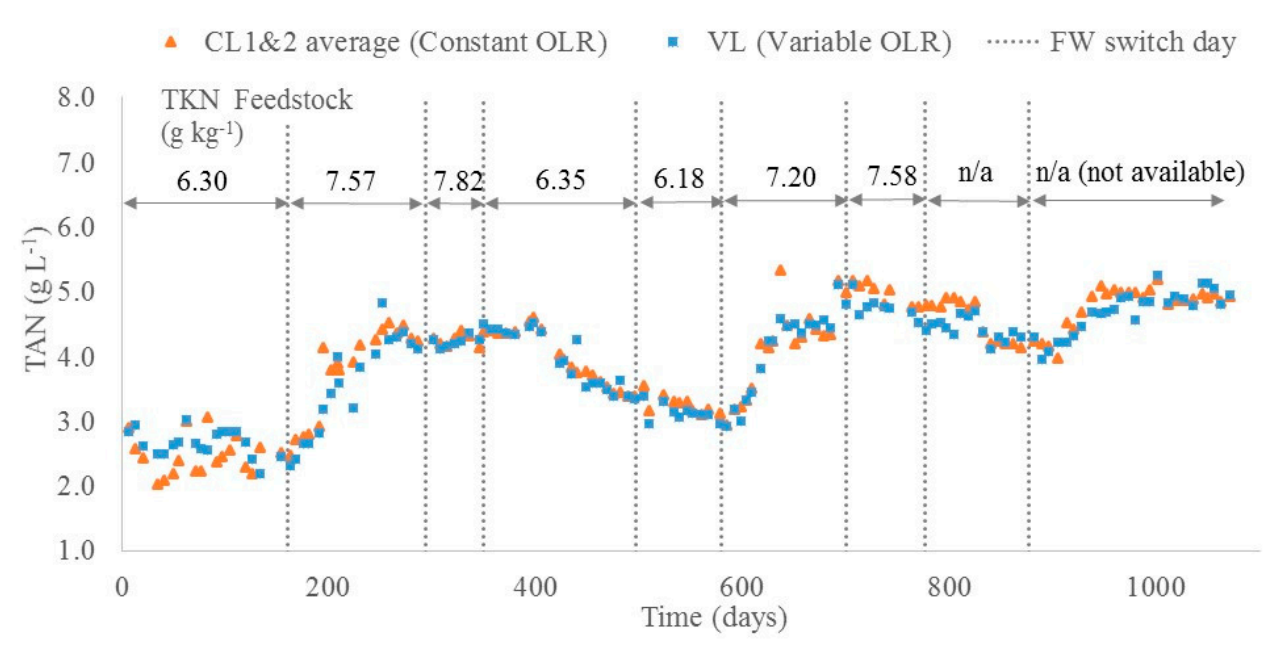

(b)

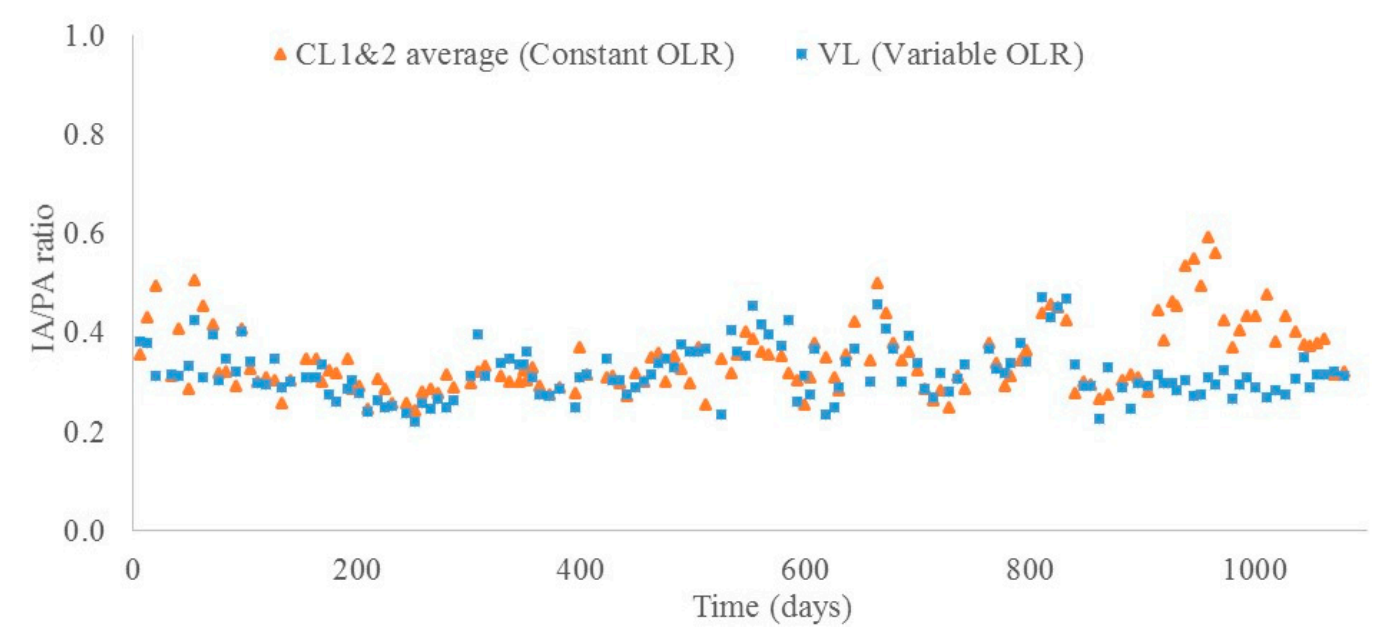

(c)

Figure 3. Operational parameters of digester VL with variable OLR and the control with constant loading (CL1\&2, average values): (a) $\mathrm{pH}$ of digester content (measured in digestate leaving the digester); (b) Ammonia of digester content (additionally, TKN of feedstock is provided); (c) Alkalinity of digester content. 


\subsection{Productivity Comparison between Variable and Constant Loading Food Waste Digesters}

Biogas methane concentrations were stable at around $58 \% \pm 2 \%$ throughout the experimental period for all digesters. The comparison between digesters with constant and variable loading started from day 182; at this time, digester VL had shown stable operation at constant loadings $\left(5.5 \mathrm{~g} \mathrm{VS} \mathrm{L}^{-1}\right.$ $\mathrm{d}^{-1}$, then $6.0 \mathrm{~g} \mathrm{VS} \mathrm{L}^{-1} \mathrm{~d}^{-1}$ ) for almost 200 days (26 weeks). When looking at the methane production during the comparison period (from day 182 until day 1068) (Figure 4), no obvious difference was found between VL and CL1\&2 when all digesters were supplemented with the full spectrum of 11 TEs (days 392-776); in all cases, the volumetric methane production (VMP) fluctuated around an average of $2.27 \mathrm{~L} \mathrm{CH}_{4} \mathrm{~L}^{-1} \mathrm{~d}^{-1}$. It is noteworthy that when larger loading variations $\left(0-10 \mathrm{~g} \mathrm{VS} \mathrm{L}^{-1} \mathrm{~d}^{-1}\right)$ were introduced in digester VL from day 632, the 28-day rolling average VMP showed stronger fluctuations. Nevertheless, in tendency the average methane production remained unchanged. When looking at the gas production from periods with different variable OLR, methane production was smoother at loading rates of 2.5-7.5 $\mathrm{g} \mathrm{VS} \mathrm{L}^{-1} \mathrm{~d}^{-1}$.

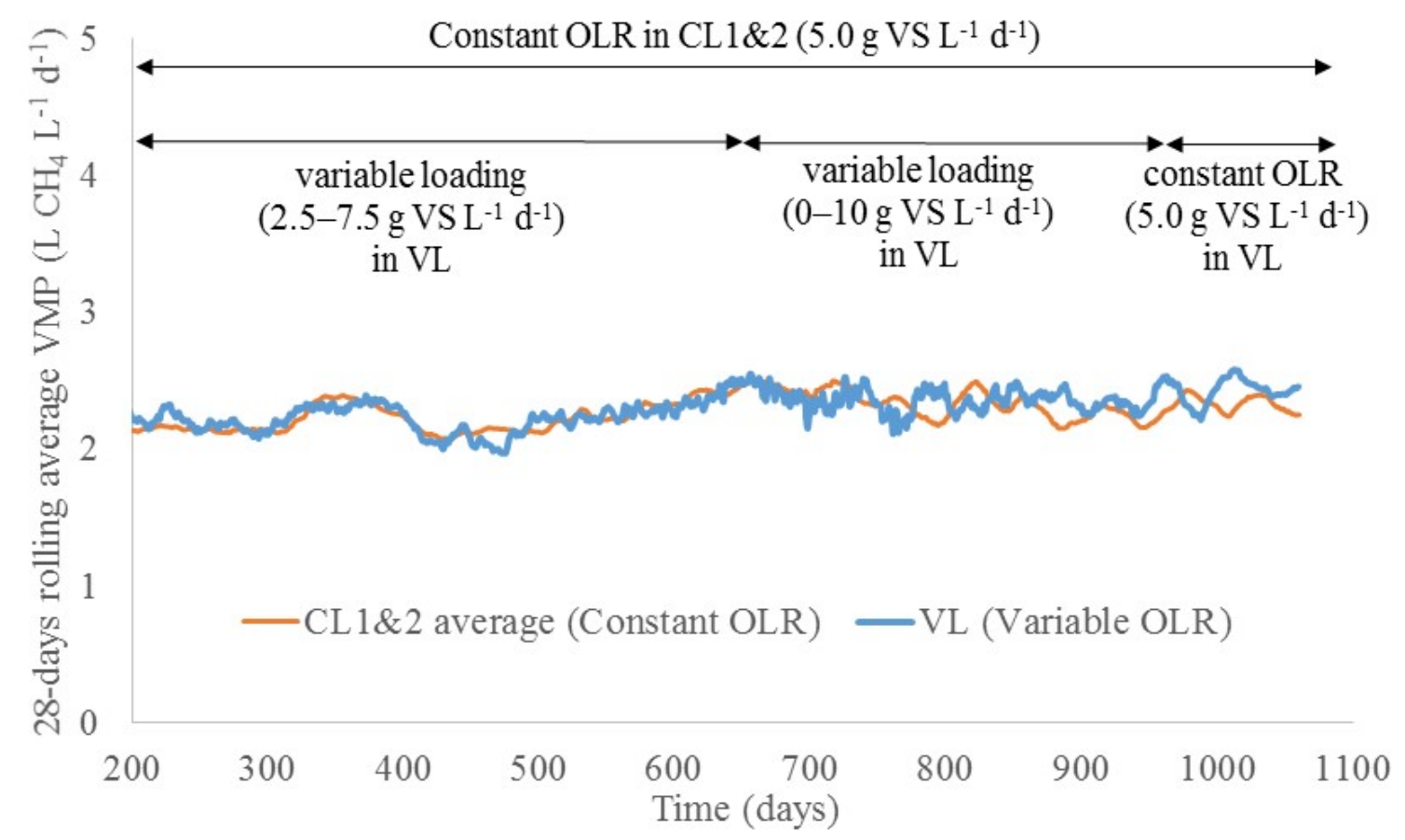

Figure 4. 28-day rolling average volumetric methane production of digester VL and control digesters CL1\&2. (Note: from day 777 on, the digesters were no longer supplemented with the full set of 11 TEs, but with Co and Se only).

A slight decrease in VMP was observed for CL1\&2 in response to the TE limitation and consequent VFA accumulation during the last months of the work. During this period, where all digesters received as TE supplementation only Se and a reduced strength of Co, digester VL maintained stable performance, with a 28-day rolling average VMP above $2.25 \mathrm{~L} \mathrm{CH}_{4} \mathrm{~L}^{-1} \mathrm{~d}^{-1}$. When shifting from the variable to a constant OLR on day 966, digester VL first responded with a slight decrease in methane production, but VMP gradually climbed back to around $2.34 \mathrm{~L} \mathrm{CH}_{4} \mathrm{~L}^{-1} \mathrm{~d}^{-1}$. The reason for these fluctuations might be an adaptation need as a result of changed loading schemes [32].

The typical biochemical methane potential (BMP) of mixed food waste of the type used in this study is 440-480 $\mathrm{L} \mathrm{CH}_{4} \mathrm{~kg}^{-1} \mathrm{VS}_{\text {added }}[17,33]$, with slightly lower values expected in single-stage semi-continuous digestion. Gray et al. [34] reported a wide range of values between 305 and $530 \mathrm{~L}$ $\mathrm{CH}_{4} \mathrm{~kg}^{-1} \mathrm{TS}_{\text {added }}$ for semi-continous digestion depending on food waste composition. In this study, the methane production of digester VL (approximately $456 \mathrm{~L} \mathrm{CH}_{4} \mathrm{~kg}^{-1} \mathrm{VS}_{\text {added }}$, calculated from the 
average VMP value) is well within the literature range, and close to the upper value in previous reports, confirming the productive performance.

\subsection{Discussion of Findings and Relevance to Commercial Food Waste Digestion}

The above results suggest that day-to-day variability in organic loading, even over quite a wide range of applied loadings, does not necessarily have a negative impact on mono-digestion of food waste when compared to digesters operated at the same average OLR with a stable loading pattern, and may even have some advantages. Based on patterns of VFA accumulation, the digester VL was in fact able to operate stably with a smaller range of TE than that needed by the digesters at a steady OLR. The reason for this difference is unknown. If the variation in loading was sufficient to bring about shock changes in digester conditions, this might lead to die-off of a proportion of the microbial population: cell lysis might then lead to release of trace elements, making these available for rapid cycling. In practice, however, operating parameters gave no indication of any shock in the variable loading digester, and if anything, the pattern of total VFA concentrations indicates greater stability than in the constant loading digesters. The variable loading digester also appeared to have a slightly higher methane productivity in comparable operating periods (e.g., days 780-960), although inevitable limitations of accuracy in gas measurement mean a greater number of replicates is needed to provide statistical certainty. There is no obvious reason for this in terms of microbial kinetics. Compared with the weekly cycle of fluctuating loading, the timescale for biological degradation of food waste in a digester is relatively long, as indicated by typical batch biochemical methane production curves for this type of material [35] and by continuing gas production after the cessation of feeding, e.g., in residual biogas production tests [36]. The average hydraulic retention time of 44 days is also relatively long, and in these conditions the range of fluctuation of daily loading is unlikely to cause shock changes or long-term perturbation in gas production. This is also supported by the stable operating parameters ( $\mathrm{pH}, \mathrm{IA} / \mathrm{PA})$ seen in all digesters. It may be the case that a more resilient community of microorganisms can be developed from the digester with changing conditions. Food waste digestion has been found to be dominated by hydrogenotrophic methanogens $[7,15]$. In previous studies it has been reported that hydrogen-utilising methanogens are more resistant to environmental changes than the acetate-utilising methanogens; hydrogen-utilising methanogens were more favourably impacted by substrate perturbation [37]. This characteristic enables the hydrogen-utilising methanogens to quickly adapt to changes in their environment $[37,38]$. In this case, however, no evidence of any clear environmental changes was observed.

While the effect of shock or transient loading on anaerobic treatment has been previously investigated, there has been little research on loading variations as tested in this study. The only similar work found, which, however, was not carried out with food waste but with a glucose feed, also confirmed that the anaerobic system was able to adapt to the periodic substrate perturbation and better results could be achieved compared to constant loading; a long-term change in microbial community was used to explain the good performance in the digester experiencing loading perturbation [37]. This study did not analyse the composition of the microbial communities; instead, it placed a focus on long-term operation and trace elements addition. It was shown that long-term mono-digestion of food waste is a reliable and highly effective process if the digestion is supported by the regular dosage of appropriate trace elements. Such dosage does not only avoid accumulation of volatile acids with subsequent process instability, but it can also stabilise a digester that is already affected by VFA accumulation. The results of this work also showed that in the event of trace element limitations, mono-digestion of food waste may be less resilient in digesters subjected to constant organic loading compared to a digester with varying organic load.

In the last stage of the experiment, re-supplementation of the full set of 11 TEs stimulated the degradation of accumulating VFAs in CL1\&2. Such accumulation had occurred despite the addition of Cobalt and Selenium. Co and Se are the two TEs that were previously found to be limiting for food waste mono-digestion, with their deficiency causing VFA accumulation [15]. The results of this study 
suggest that either some other TE was limiting, or the reduced Co concentration of $0.3 \mathrm{mg} \mathrm{L}^{-1}$ in the final part of the trial was not sufficient for the OLR of $5 \mathrm{~g} \mathrm{VS} \mathrm{L}^{-1} \mathrm{~d}^{-1}$. This highlights the need to consider a set of limiting factors and also points to the issue of co-limitation. The Liebig's law of the minimum implies that there is a single limiting nutrient which controls the yield [39], but this concept can be expanded to co-limitation due to the simultaneous scarcity of more than one nutrient. This issue of multiple potentially limiting nutrients reflects the complexity of trace metal functions at the physiological and ecological (environmental) levels, rather than at the biochemical level [40]. This is illustrated by the results of this work in the context of anaerobic digestion systems, where the extent of trace element deficiency was related to the variability or otherwise of the applied OLR, and thus, not only to the feedstock characteristics but also to the environmental parameters.

While in theory the continuous dosage of a full set of relevant trace elements might appear the most favourable option to ensure stable food waste digestion, in practice, other factors also need be considered. In commercial plants, excessive TE supplementation and strict OLR control will increase costs and management requirements. The findings of this study therefore are highly relevant for the waste management industry. The results revealed that when applying a varying instead of constant organic loading rate to a digester, the process was not disadvantaged by this operation pattern and may even have been more robust and less susceptible to inhibition. When other trace elements had been washed out, the addition of $0.3 \mathrm{mg} \mathrm{L}^{-1} \mathrm{Co}$ and $0.2 \mathrm{mg} \mathrm{L}^{-1}$ Se was sufficient to maintain a stable performance in the variable-loading digester, whereas the digesters with constant organic loading showed elevated VFA concentrations and a slight reduction in methane productivity, and required re-supplementation of the full spectrum of trace elements to achieve the same performance. Operation of food waste digesters under varying loading rates can therefore be recommended. Loading rates between 2.5 and $7.5 \mathrm{~g} \mathrm{VS} \mathrm{L}^{-1} \mathrm{~d}^{-1}$ can further be recommended.

Considering the relevance of these findings for commercial food waste $A D$, further research should explore in detail the nature of the link between OLR fluctuations and reduced TE requirement.

\section{Conclusions}

This work confirmed that mono-digestion of food waste could be operated stably and reliably with daily organic loading ranging widely from $0-10 \mathrm{~g} \mathrm{VS} \mathrm{L}^{-1} \mathrm{~d}^{-1}$ at a weekly average OLR of $5 \mathrm{~g}$ $\mathrm{VS} \mathrm{L}^{-1} \mathrm{~d}^{-1}$, and with very limited supplementation of essential trace elements, namely a dosage of $0.3 \mathrm{mg} \mathrm{L}^{-1}$ Co and $0.2 \mathrm{mg} \mathrm{L}^{-1}$ Se. No VFA accumulation or methane loss was observed for such an operating mode, whereas the control digesters operated at constant organic loading showed less stable performance and a higher risk of process inhibition. In particular, the digester with variable loading had greater resilience to trace element limitations in this study. The results indicate that the day-to-day-variation in organic loadings experienced in full-scale food waste digestion plant is unlikely to have any negative effect on biogas production or operational stability when compared to that achieved by operation at constant organic load; thus, the results also provide some confidence that findings from well-controlled laboratory-scale trials are transferrable to commercial AD plants. More studies are required to explore the theoretical basis for the difference in trace element requirements under constant and variable loading, and to quantify its practical significance.

Supplementary Materials: Data supporting this study are openly available from the University of Southampton repository at https://doi.org/10.5258/SOTON/D1266.

Author Contributions: Conceptualisation, C.J.B. and Y.Z.; methodology, Y.Z., C.J.B. and H.S.; formal analysis, H.S., Y.Z. and S.K.-B.; investigation, H.S.; resources, C.J.B.; data curation, H.S. and Y.Z.; writing-original draft preparation, H.S., Y.Z. and S.K.-B.; writing-review and editing, H.S., S.K.-B., Y.Z. and C.J.B.; visualisation, H.S. and S.K.-B.; supervision, C.J.B. and Y.Z.; project administration, Y.Z. and C.J.B.; funding acquisition, C.J.B. All authors have read and agreed to the published version of the manuscript.

Funding: The authors wish to thank the UK Government's Department of the Environment Food and Rural Affairs (Defra) and the European Union 7th Framework programme for financial support to carry out this work through grant number WR1208 and 241334 (VALORGAS), respectively.

Acknowledgments: Special thanks to Ying Jiang for providing inoculum and technical support. 
Conflicts of Interest: The authors declare no conflict of interest. The funders had no role in the design of the study; in the collection, analyses or interpretation of data; in the writing of the manuscript, or in the decision to publish the results.

\section{References}

1. Mirmohamadsadeghi, S.; Karimi, K.; Tabatabaei, M.; Aghbashlo, M. Biogas production from food wastes: A review on recent developments and future perspectives. Bioresour. Technol. Rep. 2019, 7, 100202. [CrossRef]

2. Pramanik, S.K.; Suja, F.B.; Zain, S.M.; Pramanik, B.K. The anaerobic digestion process of biogas production from food waste: Prospects and constraints. Bioresour. Technol. Rep. 2019, 8, 100310. [CrossRef]

3. Lindkvist, E.; Karlsson, M.; Ivner, J. System analysis of biogas production-Part II Application in food industry systems. Energies 2019, 12, 412. [CrossRef]

4. Ye, M.; Liu, J.; Ma, C.; Li, Y.-Y.; Zou, L.; Qian, G.; Xu, Z.P. Improving the stability and efficiency of anaerobic digestion of food waste using additives: A critical review. J. Clean. Prod. 2018, 192, 316-326. [CrossRef]

5. Pramanik, S.K.; Suja, F.B.; Porhemmat, M.; Pramanik, B.K. Performance and kinetic model of a single-stage anaerobic digestion system operated at different successive operating stages for the treatment of food waste. Processes 2019, 7, 600. [CrossRef]

6. Voelklein, M.A.; O'Shea, R.; Jacob, A.; Murphy, J.D. Role of trace elements in single and two-stage digestion of food waste at high organic loading rates. Energy 2017, 121, 185-192. [CrossRef]

7. Jo, Y.; Kim, J.; Hwang, K.; Lee, C. A comparative study of single- and two-phase anaerobic digestion of food waste under uncontrolled pH conditions. Waste Manag. 2018, 78, 509-520. [CrossRef]

8. Hegde, S.; Trabold, T.A. Anaerobic digestion of food waste with unconventional co-substrates for stable biogas production at high organic loading rates. Sustainability 2019, 11, 3875. [CrossRef]

9. Zhang, L.; Ouyang, W.; Lia, A. Essential role of trace elements in continuous anaerobic digestion of food waste. Procedia Environ. Sci. 2012, 16, 102-111. [CrossRef]

10. Wheatley, A.D.; Fisher, M.B.; Grobicki, A.M.W. Applications of anaerobic digestion for the treatment of industrial wastewaters in Europe. Water Environ. J. 1997, 11, 39-46. [CrossRef]

11. Rajeshwari, K.V.; Balakrishnan, M.; Kansal, A.; Lata, K.; Kishore, V.V.N. State-of-the-art of anaerobic digestion technology for industrial wastewater treatment. Renew. Sustain. Energy Rev. 2000, 4, 135-156. [CrossRef]

12. Lyberatos, G.; Skiadas, I. Modelling of anaerobic digestion-a review. Global Nest Int. J. 1999, 1, 63-76.

13. Gómez, X.; Cuetos, M.J.; Cara, J.; Moran, A.; Garcia, A.I. Anaerobic co-digestion of primary sludge and the fruit and vegetable fraction of the municipal solid wastes: Conditions for mixing and evaluation of the organic loading rate. Renew. Energy 2006, 31, 2017-2024. [CrossRef]

14. Pavlostathis, S.; Giraldo-Gomez, E. Kinetics of anaerobic treatment: A critical review. Crit. Rev. Environ. Sci. Technol. 1991, 21, 411-490. [CrossRef]

15. Banks, C.J.; Zhang, Y.; Jiang, Y.; Heaven, S. Trace element requirements for stable food waste digestion at elevated ammonia concentrations. Bioresour. Technol. 2012, 104, 127-135. [CrossRef]

16. Nagao, N.; Tajima, N.; Kawai, M.; Niwa, C.; Kurosawa, N.; Matsuyama, T.; Yusoff, F.M.; Toda, T. Maximum organic loading rate for the single-stage wet anaerobic digestion of food waste. Bioresour. Technol. 2012, 118, 210-218. [CrossRef]

17. Zhang, L.; Lee, Y.-W.; Jahng, D. Anaerobic co-digestion of food waste and piggery wastewater: Focusing on the role of trace elements. Bioresour. Technol. 2011, 102, 5048-5059. [CrossRef]

18. Bong, C.P.C.; Lim, L.Y.; Lee, C.T.; Klemes, J.J.; Ho, C.S.; Ho, W.S. The characterisation and treatment of food waste for improvement of biogas production during anaerobic digestion-A review. J. Clean. Prod. 2018, 172, 1545-1558. [CrossRef]

19. David, A.; Govil, T.; Tripathi, A.K.; McGeary, J.; Farrar, K.; Sani, R.K. Thermophilic anaerobic digestion: Enhanced and sustainable methane production from co-digestion of food and lignocellulosic wastes. Energies 2018, 11, 2058. [CrossRef]

20. Morales-Polo, C.; Cledera-Castro, M.D.M.; Moratilla Soria, B.Y. Reviewing the anaerobic digestion of food waste: From waste generation and anaerobic process to its perspectives. Appl. Sci. 2018, 8, 1804. [CrossRef]

21. Zhang, L.; Jahng, D. Long-term anaerobic digestion of food waste stabilized by trace elements. Waste Manag. 2012, 32, 1509-1515. [CrossRef] [PubMed] 
22. Facchin, V.; Cavinato, C.; Fatone, F.; Pavan, P.; Cecchi, F.; Bolzonella, D. Effect of trace element supplementation on the mesophilic anaerobic digestion of foodwaste in batch trials: The influence of inoculum origin. Biochem. Eng. J. 2013, 70, 71-77. [CrossRef]

23. Zhang, W.; Chen, B.; Li, A.; Zhang, L.; Li, R.; Yang, T.; Xing, W. Mechanism of process imbalance of long-term anaerobic digestion of food waste and role of trace elements in maintaining anaerobic process stability. Bioresour. Technol. 2019, 275, 172-182. [CrossRef] [PubMed]

24. Grimberg, S.J.; Hilderbrandt, D.; Kinnunen, M.; Rogers, S. Anaerobic digestion of food waste through the operation of a mesophilic two-phase pilot scale digester-Assessment of variable loadings on system performance. Bioresour. Technol. 2015, 178, 226-229. [CrossRef]

25. Kim, J.; Lee, C. Response of a continuous biomethanation process to transient organic shock loads under controlled and uncontrolled pH conditions. Water Res. 2015, 73, 68-77. [CrossRef]

26. Ferguson, R.M.W.; Coulon, F.; Villa, R. Organic loading rate: A promising microbial management tool in anaerobic digestion. Water Res. 2016, 100, 348-356. [CrossRef]

27. Jiang, Y. Anaerobic Digestion of Food and Vegetable Waste. Ph.D. Thesis, University of Southampton, Southampton, UK, 2012.

28. APHA. Standard Methods for the Examination of Water and Wastewater; American Public Health Association: Washington, DC, USA, 2005.

29. Ripley, L.E.; Boyle, W.C.; Converse, J.C. Improved alkalimetric monitoring for anaerobic digestion of high-strength wastes. J. Water Pollut. Control Fed. 1986, 58, 406-411.

30. Walker, M.; Zhang, Y.; Heaven, S.; Banks, C. Potential errors in the quantitative evaluation of biogas production in anaerobic digestion processes. Bioresour. Technol. 2009, 100, 6339-6346. [CrossRef]

31. Yenigün, O.; Demirel, B. Ammonia inhibition in anaerobic digestion: A review. Process Biochem. 2013, 48, 901-911. [CrossRef]

32. Shen, F.; Yuan, H.; Pang, Y.; Chen, S.; Zhu, B.; Zou, D.; Liu, Y.; Ma, J.; Yu, L.; Li, X. Performances of anaerobic co-digestion of fruit \& vegetable waste (FVW) and food waste (FW): Single-phase vs. two-phase. Bioresour. Technol. 2013, 144, 80-85.

33. Yirong, C. Thermophilic Anaerobic Digestion of Food Waste. Ph.D. Thesis, University of Southampton, Southampton, UK, 2014.

34. Gray, D.M.D.; Suto, P.; Peck, C. Anaerobic Digestion of Food Waste; U.S. Environmental Protection Agency: East Bay, CA, USA, 2008. Available online: https://archive.epa.gov/region9/organics/web/pdf/ebmudfinalreport. pdf (accessed on 26 January 2020).

35. Zhang, Y.; Banks, C.J.; Heaven, S. Anaerobic digestion of two biodegradable municipal waste streams. J. Environ. Manag. 2012, 104, 166-174. [CrossRef] [PubMed]

36. Walker, M.; Banks, C.; Heaven, S.; Frederickson, J. Residual Biogas Potential Test for Digestates. Waste and Resources Action Programme Project OFW004-005. 2010. Available online: http://www.wrap.org.uk/sites/ files/wrap/Residual\%20Biogas\%20Potential.pdf (accessed on 1 March 2020).

37. Xing, J.; Criddle, C.; Hickey, R. Effects of a long-term periodic substrate perturbation on an anaerobic community. Water Res. 1997, 31, 2195-2204. [CrossRef]

38. Attal, A.; Ehlinger, F.; Audic, J.M.; Faup, G.M. pH inhibition mechanisms of acetogenic, acetoclastic and hydrogenophilic populations. In Proceedings of the Anaerobic Digestion 1988: Fifth International Symposium on Anaerobic Digestion held in Bologna, Bologna, Italy, 22-26 May 1988; Pergamon Press: Oxford, UK; New York, NY, USA, 1988; pp. 71-78.

39. de Baar, H.J.W. von Liebig's law of the minimum and plankton ecology (1899-1991). Prog. Oceanogr. 1994, 33, 347-386. [CrossRef]

40. Saito, M.A.; Goepfert, T.J.; Ritt, J.A. Some thoughts on the concept of colimitation: Three definitions and the importance of bioavailability. Limnol. Oceanogr. 2008, 53, 276-290. [CrossRef]

(C) 2020 by the authors. Licensee MDPI, Basel, Switzerland. This article is an open access article distributed under the terms and conditions of the Creative Commons Attribution (CC BY) license (http://creativecommons.org/licenses/by/4.0/). 